\title{
Message from the Editorial Board
}

\section{Nepal Journal of Medical Sciences, The Official journal of Manipal College of Medical Sciences, Pokhara, Nepal.}

It gives us immense pleasure to relaunch the Nepal Journal of Medical Sciences which was in hiatus since 2014 with this new issue. Now, the journal is started with very enthusiastic and dedicated editorial board members, eminent national and international reviewers required for a high quality journal. We aspire to maintain the quality of original research, recent advances, reviews, case series and case reports of high clinical significance that will provide researchers a platform for publishing their researches. The submission process has also shifted to online platform for smooth and early review and decision policy of the journal.

Nepal Journal of Medical Sciences (NJMS) is a peer reviewed, open access, biomedical journal [ISSN 20911424 (Print) and 2091-1459] and publishes the research based articles from the field of biomedical sciences. The journal is published twice a year (January and July). Each issue of NJMS publishes Original Articles, Review Articles, Case Reports, Editorials and Letters to the Editor.

The highlights in this issue include a detailed cross-sectional study on Sickle cell disease in the Western region of Nepal. The clinical presentation and electrophoresis findings have entailed us to see the panorama of the disease and the disease burden. Another article by Ghimire et al have highlighted spectrum of findings in cervical smears with their study advocating changes in the present guideline in cervical cancer screening in Nepal.

Finally, we would like to thank all the authors, reviewers, readers, advisory board and Patron for the immense support and constant motivation which has brought forth this journal with a new editorial team and improvised scientific innovation in academia.

January 30, 2019 